\title{
Assessment of spatial representativity of X-ray tomography to study Vertical Flow Treatment Wetlands
}

\author{
German Dario Martinez-Carvajal ${ }^{\mathrm{a}, 1}$, Laurent Oxarango $\mathrm{b}^{\mathrm{b}, 2}$, Rémi Clément ${ }^{\mathrm{a}, 3}$, \\ Pascal Molle ${ }^{\mathrm{a}, 4}$, Nicolas Forquet ${ }^{\mathrm{a}, 5, *}$ \\ ${ }^{a}$ Irstea, UR REVERSAAL, 5 rue de la Doua 69616, BP 32108, Villeurbanne, France \\ ${ }^{b}$ Université Grenoble Alpes, CNRS, IRD, Grenoble INP, IGE, Grenoble, F-38000, France
}

\begin{abstract}
French Vertical Flow (VF) treatment wetlands receive raw wastewater and provide simultaneous solids/sludge and wastewater treatment. This feature among others explains why French VF treatment wetlands have become so popular for wastewater treatment of small communities (less 4,000 people equivalent) in France. For proper solids/sludge handling, the treatment wetland must be designed adequatly and specific operational and envrionmental conditions must be maintained. When these conditions are not met, accumulation of biosolids may lead to clogging. Filtration and biological treatment in french VF Treatment Wetlands are governed by mechanisms at the pore-scale. Therefore, they must be better understand to predict reliably biosolid accumulation and clogging. X-ray Computed Tomography (Xray-CT) is a promising technique to characterize in detail the morphology of the filtering media in treatment wetlands. In order to set a solid basis for the use of Xray-CT, the spatial representativity of measurements must be assessed. This issue is addressed in this study by successively analyzing spatial properties at the filter scale using Frequency Domain Electromagnetic Measurements (FDEMs), and at the pore scale using XrayCT. FDEM was used to obtain a map of the electric conductivity at the surface
\end{abstract}

\footnotetext{
* Corresponding author

${ }^{1}$ orcid id: 0000-0001-9238-1290

2orcid id: 0000-0003-1062-4303

3 orcid id: 0000-0002-5767-0772

4 orcid id: 0000-0003-3364-6118

${ }^{5}$ orcid id: 0000-0003-1154-5498
} 
of a French VF treatment wetland. The resulting map shows signs of a high level of homogeneity in the distribution of biosolids to which it is highly correlated. These results support the choice of a random sampling procedure for core samples used for Xray-CT. The following morphological properties where computed from Xray-CT after phase segmentation: phase volume fraction profiles, Specific Surface Area (SSA) profiles and pore size distributions. Samples show several similarities of pore scale properties obtained by Xray-CT independently of the sampling region and especially the same vertical gradients. FDEM measurements and Xray-CT analysis are in agreement to indicate a good influent distribution at the surface of a full-scale mature French VF treatment wetland. A particular focus is put in the definition of the limits of the deposit layer and the dense gravel layer beneath. This division allows to compare layers independently. Finally, a 2D-REV analysis performed at several depths suggests that the selected sample diameter of $5 \mathrm{~cm}$ is large enough to be representative of the heterogeneous distribution of phases at the pore-scale as long as no Phragmites are present in the $2 \mathrm{D}$-section.

Keywords: Representative Elementary Volume, Pore Size Distribution, Specific Surface Area, Constructed Wetlands, Clogging

\section{Introduction}

Treatment wetlands are a nature-based technology that present an alternative to conventional wastewater treatment technologies Sundaravadivel and Vigneswaran, 2001). Among the different possible configurations, French Ver5 tical Flow (VF) treatment wetlands have largely been adopted for treatment domestic wastewater for communities under 5,000 people equivalent in France (Morvannou et al., 2015). They are often composed of three parallel first-stage filters followed by two parallel second-stage filters filled with granular materials and planted with Phragmites Australis.

The first stage typically contains a $30 \mathrm{~cm}$ deep layer of coarse gravel $(2$ $6 \mathrm{~mm}$ ). The three first-stage cells are fed raw wastewater in an alternating 
manner; 3.5 days of feeding followed by 7 days of rest. The rules of design and implementation of French VF treatment wetlands can be found in Molle et al. (2005). As the first-stage filters are fed with raw wastewater, solid particles 15 are retained at the surface by cake filtration and in the filter media by deep bed filtration. In first-stage French VF wetlands, deep bed filtration is the predominant solids retention mechanism in newly commissioned filters, whereas cake filtration is the predominant mechanism once a deposit layer is formed. The deposit layer is the result of the accumulation of solids at the filter surface.

The entrapped solids are herein referred to as the biosolids, which are present in the deposit layer as well as the gravel filtration layer. Biosolids are characterized by their high organic matter content which ranges from $50 \%$ to nearly $90 \%$ (Kania et al. 2018) and form a porous medium whose structure and consistency evolve with time due to water content changes, organic matter mineralization and internal erosion. Kania et al. (2018) characterized the surface deposit of 14 French VF treatment wetlands and conclude that the deposit layer on mature wetlands ( $>3$ years of operation) has lower OM content, lower biodegradability, and higher humification than newly commissioned wetlands ( $\leq 3$ years of operation). Structure of biosolids impacts water and oxygen transfer as well as biological activity (Molle, 2014). The biosolids in the deposit and gravel layers are home to the microorganisms and micro-fauna responsible for degradation of pollutants. They retain part of the percolating water, and when the wetland is functioning properly, the structure of biosolids maintains a good re-oxygenation capability during rest periods, which is essential to promote mineralization of 35 organic matter (Molle, 2014).

Understanding the structural evolution of biosolids in the deposit and gravel layers is crucial since it constrains maintenance frequency and the lifespan of the treatment wetland. The deposit layer has to be removed every 10-20 years to maintain infiltration capacity, and the fouling material accumulation within

40 the granular material inevitably leads to its clogging and therefore defines the lifespan of the system (Nivala et al. 2012).

Investigations on solid retention in treatment wetlands generally focus on 
Horizontal Flow (HF) treatment wetlands, which are more prone to clogging than VF wetlands due to the fact that HF wetlands generally have a much smaller cross-sectional surface area accepting wastewater, thus they experience a higher areal organic loading rate (Knowles et al., 2011, de Matos et al., 2018). They aim at evaluating the degree of clogging and proper functioning of a treatment wetland, and provide little information regarding the underpinning mechanisms because those depend on pore scale properties. In order to gain insight into the pore scale structure, a recent study assessed the application of X-ray Computed Tomography (Xray-CT) to obtain high resolution 3D images of the porous media structure (Martinez-Carvajal et al., 2019). Promising results were achieved but the study raised the question of the spatial representativity of the samples used for Xray-CT.

Assessing the spatial representativity of Xray-CT images from French VF treatment wetlands is critical to ensure the reliability of pore scale properties that may be derived from these images. French VF treatment wetlands present heterogeneities at both the filter and the pore scales.

1. At the filter scale, two main types of macro-scale heterogeneities (Costanza60 Robinson et al. 2011)) could be considered: uneven distribution of biosolids and uneven reed density. These heterogeneities are most likely controlled by the general design of the filter including its shape and the location of feeding points. Forquet et al. (2011) computed the relative water content changes in the deposit layer over a vertical cross sectional area of a mature French VF treatment wetland (20 cm thick deposit layer) during a feeding period using time-lapse Electrical Resistivity Tomography (ERT). Water content in the deposit layer increased by $14 \%$ in a region of $50 \mathrm{~cm}$ around feeding points and by less than $4 \%$ for the rest of the analyzed vertical cross-section. Heterogeneities in the deposit layer are likely to evolve in French VF treatment wetlands due to the reed growth 70 and colonization, the progressive accumulation of biosolids in the pore space of the gravel layer, and the mineralization of biosolids in both the deposit layer and gravel layer. The older a French VF treatment wetland is, the smoother these heterogeneities become. This is especially the case for plants because 
it may take several years before the plant cover is fully established. Factors affecting the speed of plant establishment include plant species, age, availability of adequate micronutrients, and adaptation to the environmental conditions found in in treatment wetlands (Lombard-Latune et al., 2018; Chazarenc et al. 2009).

At the pore scale, the French VF treatment wetlands are comprised of gravel, biosolid, water and void space. The representativity of samples at this scale depends on the distribution of these phases in terms of volumetric contents and characteristic sizes. Many studies rely on the computation of the Representative Elementary Volume (REV) to assess the spatial representativity of samples (Costanza-Robinson et al., 2011, Al-Raoush and Papadopoulos, 2010, Li et al.

${ }_{85}$ 2009). The 'p'-REV is the minimal volume of a sample from which the volumeweighted average value of the property 'p' is no longer dependent on the volume of the sample and then becomes representative. Several methods have been proposed to assess the REV size. They are all based on iterative processes where the volume integral of the property 'p' is computed over volume increasing in size but they differ on the origin of this sampling volume: a single point taken in the middle of the sample (Costanza-Robinson et al., 2011; Al-Raoush and Papadopoulos, 2010) or multiple points randomly distributed over the sample (Zhang et al., 2000, Ramírez et al. 2019). In porous media, the most common property analyzed is the void volume fraction (e.g., porosity), but REV of other properties, such as specific surface area (SSA), moisture saturation, coordination number, or local void ratios are also studied Al-Raoush and Papadopoulos, 2010). A subject of great interest is to assess whether or not achieving the porosity-REV implies that REV for other properties is achieved too. Some authors have investigated this question and their conclusions vary. Al-Raoush 100 and Papadopoulos (2010) found that the porosity-REV is smaller than the REV for particle size distribution, local void ratio and coordination number for sand samples with different uniformity/gradation degrees. Costanza-Robinson et al. (2011) found larger porosity-REVs than REVs for interfacial area $\left(A_{i}\right)$ and moisture saturation $\left(S_{w}\right)$ in wet samples of glass beads and silica sands. However, 
of the lack of a robust criteria to determine whether the averaged value of the property 'p' is constant or not.

This work demonstrates the spatial representativity of samples extracted from a first-stage French VF treatment weltand by examining the heterogeneities present at both the pore scale and the filter scale. This is achieved by (i) determining whether the size of the samples is large enough to ensure spatial representativity at the pore scale, and (ii) quantifying the similarity of pore scale structure of samples from the same filter extracted at different locations.

\section{Materials and Methods}

\subsection{Study site}

The study was carried out on a full scale French VF treatment wetland in Montromant (Rhône, France). It was designed according to French standards defined in Molle et al. (2005) for 200 people equivalent. It has two treatment stages: a first stage consisting of four parallel filters, and a second stage containing two parallel filters. Each filter in the first stage is approximately 64 $m^{2}$. Since its commission in 1994, three of the four filters in the first stage were in operation. In 2009, the deposit layer of these filters was removed and the fourth filter in the first stage was put into operation. The duration of the feeding period remained 3.5 days and the rest period was increased from 7 days $\left(d_{10}=2 \mathrm{~mm}\right.$ and uniformity coefficient $\left.=1.5\right)$. Based on regulatory monitoring measurements performed in 2013, the suspended solids (SS) and the Chemical Oxygen Demand (COD) loads applied to the first stage filter in operation were $158 \mathrm{~g} \cdot \mathrm{m}^{-2} d^{-1}$ and $262 \mathrm{~g} \cdot \mathrm{m}^{-2} d^{-1}$, respectively. More details on the site description can be found in Martinez-Carvajal et al. (2019). All measurements were conducted on a single first stage wetland cell. 


\subsection{Electrical conductivity mapping}

Gravel is a geomaterial having low Electrical Conductivity (EC). On the other hand, the water and organic matter constituting the biosolids present ments, the device was swept over the investigated area of the filter. Therefore 
measurements were carried out at the end of winter 2018, when Phragmites were cut off. The pipes that dispose wastewater at the treatment wetland surface are made of plastic and thus do not interfere with the measurements. Data were collected on a regular grid $(\Delta x=0.5 \mathrm{~m}, \Delta y=0.5 \mathrm{~m})$. The map of the EC was computed using a linear interpolation between the points of the grid.

EC data were filtered to eliminate defective points by applying two thresholds:

- Electrical conductivity values below $0.1 \mathrm{mS} \cdot \mathrm{m}^{-1}$, the limit of detection of CMD-Tiny, were not taken into account

- Phase changes exceeding $2.5 \mathrm{ppm}$ were eliminated. Measurement of the in-phase component of the signal indicates magnetic disturbance in the ground. If the phase change is above this threshold, the linear relationship between the electrical conductivity and the quadrature component is not verified and the McNeil relationship is thus not applicable (McNeill, 1980).

\subsection{Sampling}

FDEM measurements were also used to drive the sampling procedure for Xray-CT. Based on the map of electrical conductivity, three regions, approximately $1 \mathrm{~m}$ in diameter, were selected. At the beginning of a rest period, two samples per region, named A and B, were extracted. The samples consisted of cylinders of $5 \mathrm{~cm}$ in diameter and $16 \mathrm{~cm}$ in height. The extraction method is described in detail in Martinez-Carvajal et al. (2019). Samples were identified with a number corresponding to the sampling region and a letter (A or B).

${ }_{85}$ Cores A and B were sampled as close as possible to each other. The height of the samples was large enough to contain all the deposit layer and at least 5 $\mathrm{cm}$ of the gravel layer. The cross-sectional area of samples was approximately $19 \mathrm{~cm}^{2}$. After the extraction, all the samples were sealed with a plastic film and stored at $5{ }^{\circ} \mathrm{C}$ to avoid water evaporation. They were scanned by X-ray tomography within the following 72 hours. 


\subsection{X-ray tomography and segmentation}

Tomographies were performed with a tomograph EasyTom XL (RX Solutions) at University Grenoble Alpes. The scanner was equipped with a $150 \mathrm{kV}$ tungsten X-ray tube. It was operated with an accelerating voltage of $140 \mathrm{kV}$ and a current of $200 \mu \mathrm{A}$. A $0.5 \mathrm{~mm}$ copper foil filter was put in front of the X-ray source to reduce beam-hardening artifacts. 4480 projections distributed among $360{ }^{\circ}$ were recorded. The sensor area was $250 \times 200 \mathrm{~mm}$ with $2084 \times$ 2084 pixels. Scans were obtained using a helicoid acquisition. The data were reconstructed using a cone-beam algorithm (X-Act 2.0, RX Solutions). 3D images consist of approximately $1500 \times 1500 \times 4600$ voxels $(l \times w \times h)$ with a voxel size of $35 \mu \mathrm{m}$. No contrast enhancing was performed during the reconstruction. The reconstructed data were then processed and visualized with the public domain ImageJ/Fiji (Schindelin et al., 2012) and Python (Van Rossum and Drake Jr 1995) sharewares. A three-phase segmentation of the scans was performed based on a region growing algorithm developed by Hashemi et al. (2014) and adapted in a previous study (Martinez-Carvajal et al. 2019). Segmentation consists in the attribution of the voxels of a digital image to a single phase based on their gray values and those of their neighbors. This algorithm allows to successfully segment three phases: voids, biosolids, and gravels.

In images containing multiple phases, the ranges of gray values corresponding to each phase overlap due to small differences in absorption coefficients, thus generating noise. Segmentation is often preceded by pretreatment routines to facilitate the voxels attribution such as smoothing filters to reduce noise. In this work, the median filter used in Martinez-Carvajal et al. (2019) has been replaced by an anisotropic filter (Bhattad et al., 2013; Pilny and Janacek 2006. Tschumperl and Deriche, 2003). A simple diffusion filter reduces noise by smoothing values proportionally to the gradient of gray value. However, it tends to blur the edges between different phases (i.e. interfaces between gravel, voids and biosolids). In anisotropic diffusion, noise is reduced by applying smoothing in the edge tangential direction but not in the normal direction which preserves the location of interfaces better. 
The application of the anisotropic filter leads to a better recognition of voxels presenting a Partial Volume Effect (PVE). PVE appears when two phases are taken into account into a single voxel, thus making it more difficult to assign the voxel to a single phase. These voxels are preferentially located at edges of phases, where the gray level gradient is maximum. PVE voxels were defined by thresholding the image of the gradient of gray values using the FIJI's routine 'Find Edges' (Martinez-Carvajal et al., 2019).

\subsection{Post-treatment}

\subsubsection{Morphological properties}

Three pore scale measurements were obtained by image post-processing (after segmentation): volume fraction profiles for each phase (voids, gravel, and biosolids), SSA profiles for the interface between voids and biosolids and pore size distributions of the void phase.

Volume fraction profiles were obtained by computing the ratio between the number of voxels belonging to each phase and the total number of voxels (the sum of the three phases) for each horizontal slice. Profiles were smoothed using a moving average window of 57 voxels in depth with a displacement of one voxel at a time. 57 voxels $(2 \mathrm{~mm})$ corresponds to the $d_{10}$ value of the gravel size distribution.

The SSA is obtained by dividing the surface of the interface between voids and biosolids by the bulk volume. The surface of the interface between voids and biosolids was computed using the Cauchy-Crofton cutting line method Legland et al., 2011; Lehmann and Legland, 2012, Santaló, 2004). This method allows to numerically estimate the interface areas with a better accuracy than the direct counting of interface voxels, which presents a "staircase effect". In addition, it has a much lower computational cost than methods based on surface meshes. For each voxel belonging to the void phase located at the interface with the biosolid phase, the algorithm consists in counting the number of neighboring voxels in the biosolid phase with respect to three families of connection: 1connected (face-connection), $\sqrt{2}$-connected (2D diagonal/edge connection) or 
$\sqrt{3}$-connected (3D diagonal/corner connection). The number of connections of each type is then multiplied by a characteristic coefficient obtained from the Voronoi tesselation of the unit sphere. The sum of these contributions results in the value of the surface. The specific surface area profile was obtained by computing the specific surface areas of subsamples 57 voxels in height without overlay.

The pore size distribution was obtained by computing the local thickness map of the void phase of the segmented images. The local thickness map of a 3D object is another 3D image where each voxel stores the diameter of the largest sphere that fits inside the object and contains the voxel (without being necessary centered at the voxel). The computation of the map was conducted using the FIJI plugin called Local Thickness Map (Hildebrand and Rüegsegger. 1997, Saito and Toriwaki, 1994). This mehtod has previously been used to 265 compute pore size distributions in sandstone (Chang et al. 2016).

\subsubsection{Representative Elementary Volume (REV)}

The REV for the volume fraction of voids, biosolids and gravels were computed for one of the samples (MON1A) at several 2D slices (1-voxel thick) corresponding to four different depths in the sample. They are herein referred to as void-REV, biosolid-REV and gravel-REV. The average volume fraction of each of the three phases is computed for concentric circular windows of increasing radius ranging from 1 voxel to the sample radius. The volume fractions of each phase are then plotted as a function of the radius of the circular windows. The analysis of several 2D sections using concentric circular elements was preferred to a 3D analysis (using concentric cylinders) because (i) the influence of Phragmites on the sample structure is easier to analyse and (ii) French VF treatment wetlands present a natural vertical gradient of phase distribution in the direction of the water flow due to cake and bed filtration of solid particles (Martinez-Carvajal et al., 2019). Therefore, 3D REV would integrate vertical 280 variations of phase volume fractions that are already analyzed in volume fraction profiles and introduce a bias regarding the minimum representative sample 


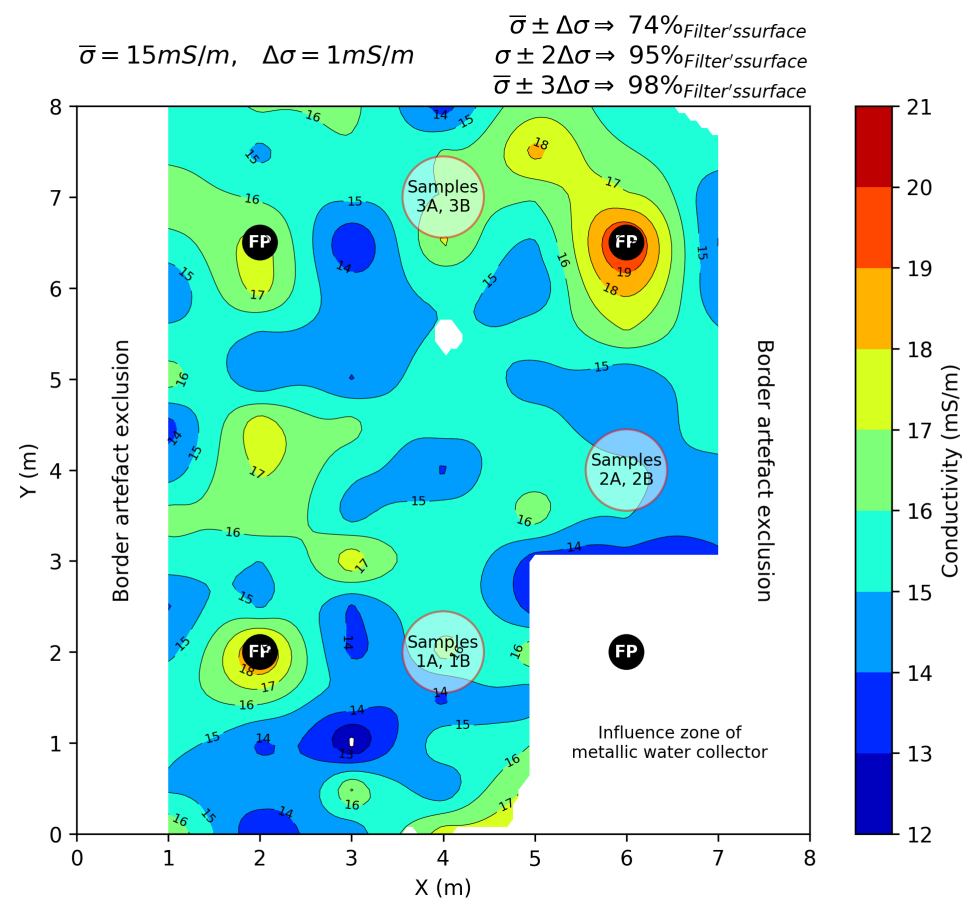

Figure 1: Electrical conductivity map of the filter. FP stands for feeding points. Samples regions are indicated on the map. $\bar{\sigma}$ is the electrical conductivity mean value and $\Delta \sigma$ is the chosen threshold value for the measurement sensitivity

diameter.

\section{Results and Discussion}

\subsection{FDEM and choice of sampling points}

A map of the electrical conductivity of the topmost layer of the filter is drawn according to the methodology presented in SECTION 2.1 (Figure 1). This method captures the spatial variation of biosolid content over the entire filter surface. In highly conductive materials, Clement et al. (2018) and McNeill (1980) advised to only consider variation $(\Delta \sigma)$ larger than $6 \%$ of the mean value of $\mathrm{EC}\left(\Delta \sigma=1 \mathrm{mS} \cdot \mathrm{m}^{-1}\right.$, in our case) as significant compared to the manufacturer specification which considers variations larger than $\Delta \sigma=0.1 \mathrm{mS}$. $m^{-1}$ as significant. EC values within the ranges $( \pm \Delta \sigma)$ and $( \pm 2 \Delta \sigma)$ correspond 
to $75 \%$ and $95 \%$ of the filter surface, respectively. The high values of EC (13$17 \mathrm{mS} \cdot \mathrm{m}^{-1}$ ) observed for almost the entire surface of the filter indicate a homogeneous distribution of organic matter and water embedded in the biosolids because biosolids present a high moisture content due to capillarity effects and the presence of biomass.

The remaining surface corresponds to circular areas of less than $1 \mathrm{~m}$ in diameter located around the feeding points. A significant increase of the EC in these regions is observed, which is most likely a result of the higher organic matter content and water content in the biosolids and/or a larger content of biosolids in depth. These results are complementary to those presented in Forquet et al. (2011) where electrical resistivity measurements showed that, during a feeding period, the water content in a first stage French VF treatment wetland increased by approximately $7-14 \%$ at distances less than $0.5 \mathrm{~m}$ from the feeding points and by less than $4 \%$ for the rest of the filter. When water exits the feeding pipes, it infiltrates predominantly in the vicinity of a feeding point, leading to a preferential accumulation of biosolids and water retained by capillarity. Except for these localized effects, variations of EC in Figure 1 do not depend on the distance to the feeding points. This homogeneity may be explained by the age of the French VF treatment wetland (25 years) as it is observed that the homogeneity of the biosolid distribution depends on the age of the facility and the applied load (Molle, 2014).

Values in the white regions on Figure 1 are not plotted as they correspond 315 to parts of the filter with specific features that induce artefacts (Clement et al. 2018): (i) the freeboard produces an artifact that extends over $1 \mathrm{~m}$ from the filter edges. (ii) at the bottom-right part, a metal lid covers the water collector at the outlet of the the French VF treatment wetland which also induces an artifact.

Xray-CT complements the data acquired by electromagnetic mapping. XrayCT gives insight on the vertical structure and phase distribution of the filter as its resolution (about 100 times better than FDEM data) gives more detail. FDEM can drive the choice of the Xray-CT sample location by identifying areas 
with homogeneous water and biosolid content. Consequently, Xray-CT sample

These observations match the current understanding of filtration mechanisms in French VF treatment wetlands. The deposit layer is built up by cake filtration. This leads to a higher content of biosolids in the deposit layer than in the gravel layer. The high resolution of Xray-CT provides interesting details on illustrate that there is no clear delimitation of the end of the deposit layer and the beginning of the gravel layer at the micro-scale. In particular, the end of the deposit layer cannot be defined as the depth at which the first gravel appears, as some gravel can be observed near the surface at depths where the biosolid 350 (Rosato et al., 1987): fine particles of the biosolids move beneath some pieces of gravel forcing them to migrate upwards. However, a systematic transition 


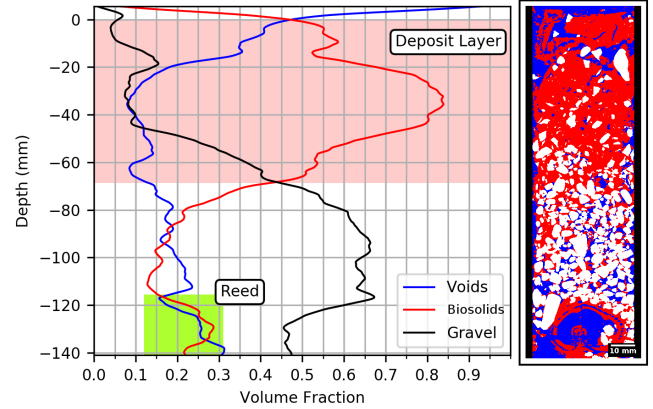

(a) sample MON1A

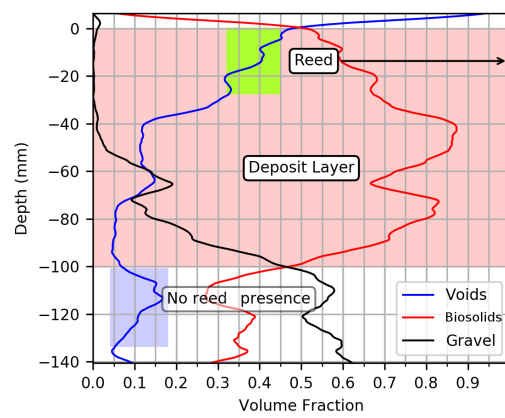

(c) sample MON2A

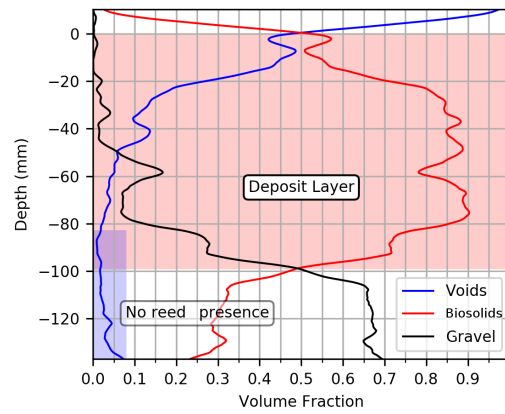

(e) sample MON3A
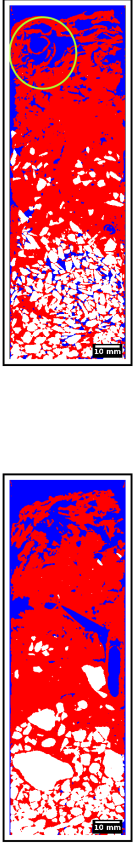

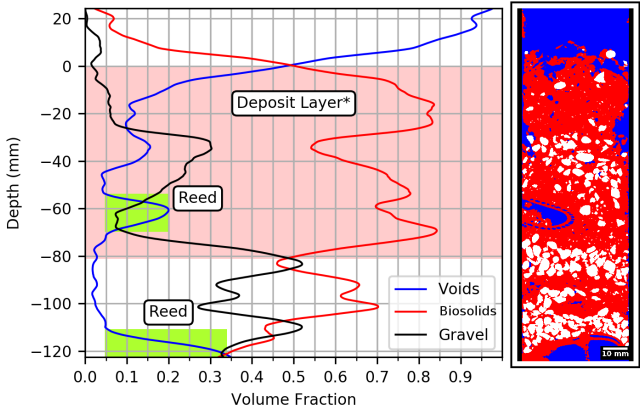

(b) sample MON1B

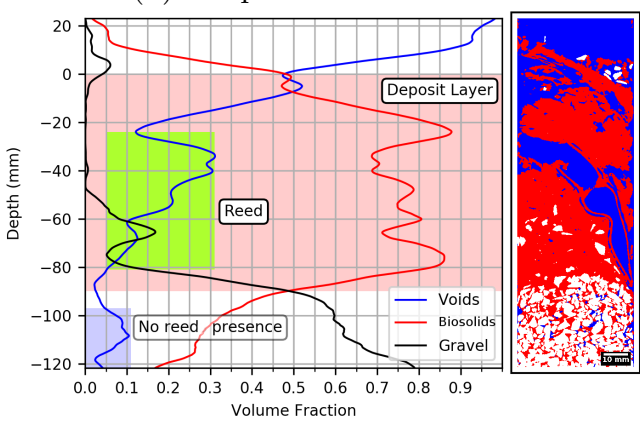

(d) sample MON2B

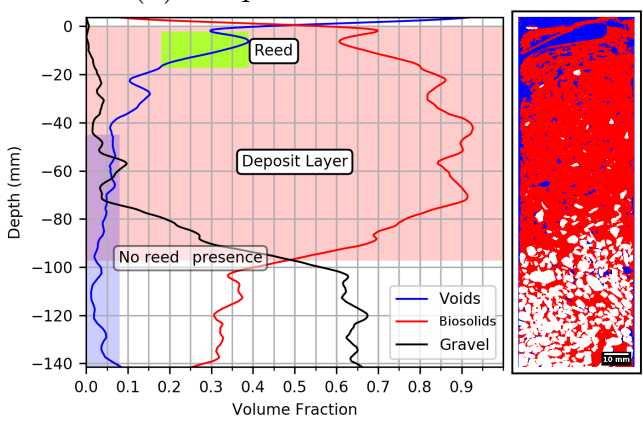

(f) sample MON3B

Figure 2: Volume fraction versus depth of each phase (voids, biosolids, and gravels) (on the left), $2 \mathrm{D}$ vertical slice of the segmented image (on the right) 
Table 1: Thickness and average volume fractions of the constitutive phases for the different layers

\begin{tabular}{|c|c|c|c|c|c|}
\hline & \multirow[t]{2}{*}{ Sample } & \multicolumn{3}{|c|}{ Volume fraction (-) } & \multirow[t]{2}{*}{ Thickness (mm) } \\
\hline & & Voids & Biosolids & Gravels & \\
\hline \multirow{6}{*}{$\begin{array}{l}\text { Deposit } \\
\text { layer }\end{array}$} & MON1A & 0.18 & 0.65 & 0.16 & 69 \\
\hline & MON1B & 0.13 & 0.71 & 0.16 & 81 \\
\hline & MON2A & 0.19 & 0.71 & 0.10 & 100 \\
\hline & MON2B & 0.21 & 0.72 & 0.06 & 89 \\
\hline & MON3A & 0.14 & 0.77 & 0.09 & 99 \\
\hline & MON3B & 0.11 & 0.80 & 0.09 & 97 \\
\hline \multirow{6}{*}{$\begin{array}{l}\text { Gravel } \\
\text { layer }\end{array}$} & MON1A & 0.21 & 0.21 & 0.58 & 73 \\
\hline & MON1B & 0.08 & 0.53 & 0.40 & 42 \\
\hline & MON2A & 0.10 & 0.34 & 0.56 & 41 \\
\hline & MON2B & 0.06 & 0.31 & 0.63 & 33 \\
\hline & MON3A & 0.03 & 0.32 & 0.65 & 38 \\
\hline & MON3B & 0.03 & 0.34 & 0.63 & 44 \\
\hline \multirow{6}{*}{$\begin{array}{l}\text { Deposit } \\
\text { layer + } \\
\text { Gravel } \\
\text { layer }\end{array}$} & MON1A & 0.21 & 0.42 & 0.36 & 142 \\
\hline & MON1B & 0.23 & 0.57 & 0.20 & 123 \\
\hline & MON2A & 0.19 & 0.59 & 0.22 & 141 \\
\hline & MON2B & 0.28 & 0.54 & 0.18 & 122 \\
\hline & MON3A & 0.16 & 0.61 & 0.23 & 137 \\
\hline & MON3B & 0.10 & 0.65 & 0.25 & 141 \\
\hline
\end{tabular}

is observed between the deposit layer (where the void and biosolid phases are predominant) and the gravel layer (where the biosolid and gravel phases are

predominant). The inversion of phase predominance is readily identified at the intersection of the biosolid and gravel curves which occurs around $40-50 \%$ of volume fraction. This systematical behavior is used to define the lower limit of the deposit layer. Similarly, the upper limit of the deposit layer is defined at the intersection of the void and biosolid curves at the top of the samples.

The thickness of the deposit layer is represented by the red-shadowed regions in Figures $2 \mathrm{a}$ to $2 \mathrm{f}$. Furthermore, by setting this criterion, it is possible to compare specific features of the deposit layer and gravel layer (Table 1).

Deposit layer. Most of the volume in the samples corresponds to the deposit layer. The total thickness of the deposit layer ranges between 7 and $10 \mathrm{~cm}$. Samples MON2A, MON3A and MON3B have a deposit layer thicknesses of ap- 
proximately $10 \mathrm{~cm}$. Samples MON1A, MON1B and MON2B have a slightly thinner deposit layer: $7 \mathrm{~cm}, 8 \mathrm{~cm}$ and $9 \mathrm{~cm}$, respectively. Samples from sampling region 1 show the lowest biosolid volume fraction $(0.65-0.70)$ followed by sampling region $2(0.71)$ and $3(0.77-0.80)$. Xray-CT can capture small variations of the biosolid volume fraction and of the layer thickness. Nevertheless, the differences obtained among the samples (from 0.1 to $3.0 \mathrm{~cm}$ in the deposit layer, and from $1 \%$ to $15 \%$ in the biosolid volume fraction) may be explained by local compaction associated to maintenance operations (i.e. person walking on the filter) or local accumulation of stems and leaves. It creates a micro-topography that differs from the heterogeneities usually induced by uneven effluent distribution. This micro-topography is not captured by spatial averaging technique like FDEM but is readily observable by Xray-tomography.

To better estimate how the void volume fraction evolves in depth, the contribution of Phragmites has to be removed. For over half of the sample, the void volume fraction reaches values ranging from $0 \%$ to $15 \%$. High values near the surface may visually be explained by the presence of a large number of macropores which is probably the sign of an ongoing consolidation of fresh biosolids or caused by movement of Phragmites stems. Finally, it must be pointed out that depsite the low void volume fraction observed at the bottom of the deposit 385 layer, water infiltrates normally on the surface of the filter.

Gravel layer. The phase distribution in the gravel layer (the region below the deposit layer in Figures 2a to 2f tends to be more homogeneous than in the deposit layer with the exception of samples MON1B and MON2B. In other samples where Phragmitesare not present, gravel volume fraction ranges from $390 \quad 0.55$ to 0.65 which is agreement with the value of 0.65 reported by Kim and Forquet (2016). Depending on the sample, the average value of biosolid volume fraction ranges from 0.21 to 0.53 with a decreasing gradient with increasing depth. The average void volume fraction are less than 0.1 with the exception of sample MON1A. Similar to what has be mentioned earlier for the deposit layer,

the high biosolid content and the low porosity appears to not be detrimental 
to filter operation. It seems that the volume of void space is still large enough to provide gravity-driven infiltration. The void phase identified by tomography corresponds to pores larger than the tomography's resolution $\left(35 \mu \mathrm{m} \cdot \mathrm{voxel}^{-1}\right)$. These large pores are often referred-to as the 'open porosity'. To access the micro-porosity inside the biosolid phase it would be necessary to enhance the resolution, which would require smaller sample size. The choice of sample size is discussed in SECTION 3.3. In a gravel area with no biosolids, the gravel fraction goes up to $80 \%$, whereas samples show that its fraction could be $5 \%$ to $10 \%$ lower (sample MON2B and MON2A, respectively) where fouling material is present. This result contradicts the usual understanding of clogging that considers a constant gravel volume fraction. Such a decrease in gravel density is likely due to the mechanical action of the biosolids during its invasion of the gravel pore space as mentioned in previous section.

Singularities. The more accurate the measurement is, the more likely heterogeneities are likely to be seen. These singularities may be explained for most of the cases by specific local features like the presence of reeds.

The presence of Phragmites alters considerably the void distribution and biosolid accumulation in the samples. This is particularly the case for sample MON1B (Figure 2b), where the criterion to define the limits of the deposit ${ }_{15}$ layer proposed in this work fails to describe accurately the sample. The green regions in Figures 2a to 2f show clearly how the major fluctuations in phase distribution are caused by Phragmites. A more homogeneous description could be obtained if Phragmites and their Aerenchyma were segmented separately. To assess this hypothesis, the image treatment methodology should evolve to a 4-phase segmentation procedure. This is particularly challenging since the contrast between the plant tissues and the biosolids in the gray-scale image is weak. A methodology based on shape recognition might enable such a segmentation.

There are also some fluctuations in the profiles that are not caused by the presence of a Phragmites (blue-shadowed regions in Figures 2a to 2f). For instance, in samples MON2A and MON2B, the gravel layer contains a zone of 


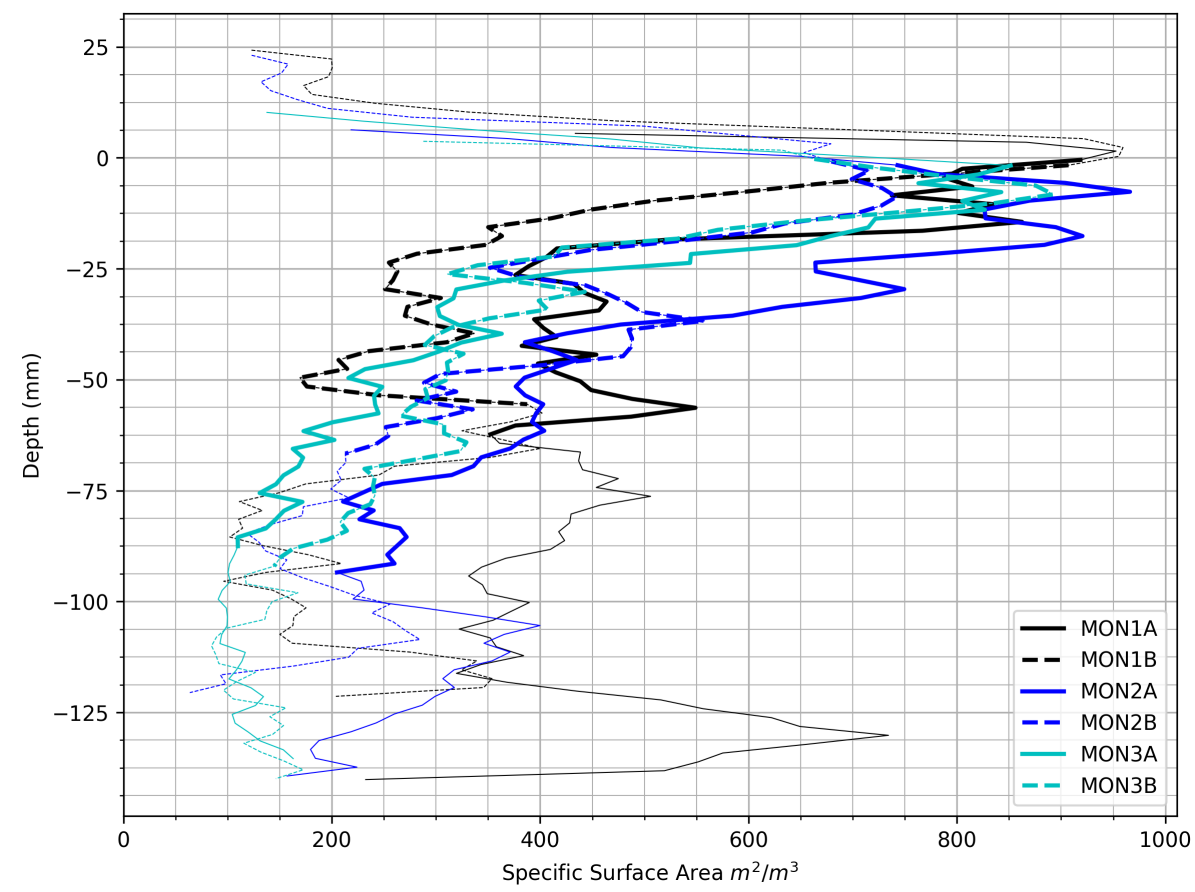

Figure 3: Specific Surface Area (SSA) versus depth. Wide lines correspond to the deposit layer

relatively low biosolid volume fraction. A simulation of solids transport at the pore scale may help to understand why there is no biosolids in some part of the gravel.

\subsubsection{Specific surface area profiles}

The Specific Surface Area (SSA) is an important parameter for biochemical reactions and for multiphase solute transport modeling. In French VF treatment wetlands, the SSA of the interface between voids and biosolids is of particular interest. Oxygen transport is a limiting factor for nitrification and mineralization (Dotro et al. 2017). Oxygen diffuses quickly in the air-filled porosity and most of the biological degradation occurs within biosolids (Molle, 2014), therefore the oxygen transfer from the air-filled porosity to the biosolids depends on the SSA of the interface between biosolids and voids.

The SSA profiles of the interface between biosolids and voids in Figure 3 show 
Table 2: Mean Specific Surface area (SSA) of the sample constitutive layers

\begin{tabular}{ccccccc}
\hline & \multicolumn{5}{c}{ Specific Surface Area $(\mathrm{SSA})\left(m^{2} \cdot m^{-3}\right)$} \\
& MON1A & MON1B & MON2A & MON2B & MON3A & MON3B \\
\hline Deposit layer & 539 & 362 & 507 & 468 & 367 & 384 \\
Gravel layer & 437 & 222 & 275 & 184 & 112 & 126 \\
\hline
\end{tabular}

similar trends independently of the sample location. The sections where lines

440 1999, Austin et al., 2007). In these approaches, the SSA is computed or mea- 
sured considering macroscopic features of the media, such as the surface of granular media or the surface of the biofilm developing around the granular material and plant roots. The predicted values in Polprasert and Khatiwada (1998) and Khatiwada and Polprasert (1999) are considerably lower than the values obtained in this study as they computed the 'effective specific surface area' based on bio-kinetic models. The effective SSA is the active surface where biological reactions can take place. In fact, bacteria would only develop in a small fraction of all the available surface and thus the effective SSA should be lower than the value estimated by this method.

Measurements relying on adsorption/desorption methods yield values 10000 times larger than those of this study. These are molecular scale measurements. which depend on the molecule that is being adsorbed/desorbed (typically ${ }_{475} \mathrm{H} 2 \mathrm{O}(\mathrm{g})$ or $\left.\mathrm{N} 2(\mathrm{~g})\right)$. In the work of Kania et al. (2018), the studied samples were taken from the deposit layer of French VF treatment wetlands. Values with a similar order of magnitude of SS were found by Poots and McKay (1979) and Szafranek-Nakonieczna and Bennicelli (2010) when measuring the specific surface of peat using $N_{2}$ adsorption, mercury porosimetry and solution isotherms. However the measurements vary depending on the chemical and physical interactions between the adsorbate and the absorbent. Most of these surfaces are not accessible to Xray-CT methodology due to their location within the biosolids and because characteristic pore sizes are smaller than the scan resolution.

The use of SSA values for the interface between voids and biosolids as parameters in models for transport and reaction in French VF treatment wetlands must be carried out carefully. The measurements from this work are relevant for macroscopic transport of solutes within the open porosity, such as oxygen transport from the atmosphere to the biosolids, and are not relevant for microscopic transport phenomena inside the biosolids, such as adsorption and desorption or biochemical kinetic models.

Compared to other methods, the advantages of using X-ray tomography images to measure the SSA are: (i) a high spatial resolution compared to experimental methods that usually provide a global estimate only, (ii) measurements 
rely on the actual geometry extracted from the segmented images and there is no assumption of specific pore shape, or particle shape (iii) there is no bias induced by chemical or physical interactions between the adsorbate and the adsorbent. However, the computed values do not represent SSA of pores smaller than the resolution of the tomography, and thus, this approach does not take into account the small capillary pores within the biosolid phase. Nonetheless, small pores are often saturated with water thus limiting oxygen transfer during the feeding period and a part of the rest period.

\subsubsection{Pore Size Distribution (PSD)}

The description of the pore structure of treatment wetlands is critical for the understanding of pore scale phenomena like fluids flow or solute and suspended solid transport. In Figure 4, the PSD of all the samples is plotted for the deposit and gravel layers separately. There is a remarkable similarity among samples regarding the mode, and the dispersion of pore sizes around the median values (Figure 5).

Omitting small peaks at the largest sizes, $(>3 \mathrm{~mm})$ which correspond to reed cavities, the distributions in Figures $4 \mathrm{a}$ and $4 \mathrm{~b}$ can be described as unimodal. The mode ranges from 0.40 to $0.75 \mathrm{~mm}$, ( $\sim 10$ to 20 voxels) independently of the layer (deposit or gravel) and the sample location.

In the deposit layer (Figure 6), pores smaller than $4 \mathrm{~mm}$ represent more than $90 \%$ of the void volume for all samples, except for sample MON2B which presents a Phragmites occupying a large volume within the deposit layer. In the gravel layer (Figure 6), the range of pore size is narrower. Pores smaller than $3 \mathrm{~mm}$ correspond to more than $95 \%$ of the void volume, except for samples MON1A and MON1B which have a Phragmites at the bottom of the sample. Some pores in the deposit layer may have been enlarged by movement of Phragmites as it can be seen in sample MON2A (Figure 2c), but this behavior has been observed clearly only once. In contrast, samples MON1B and MON2B contain large Phragmites deeper into the sample and no pore enlargement is observed arround them. The only relevant difference among the samples is the 

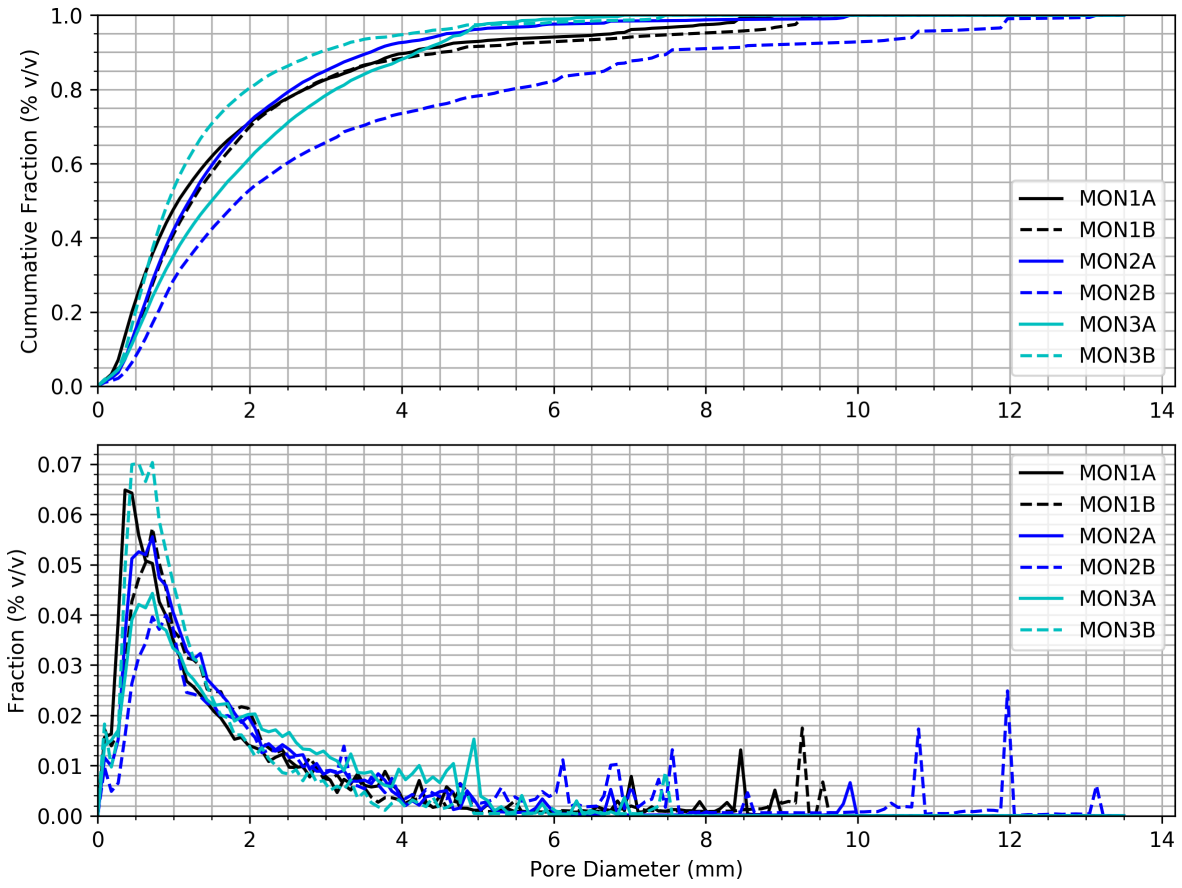

(a) Deposit layer
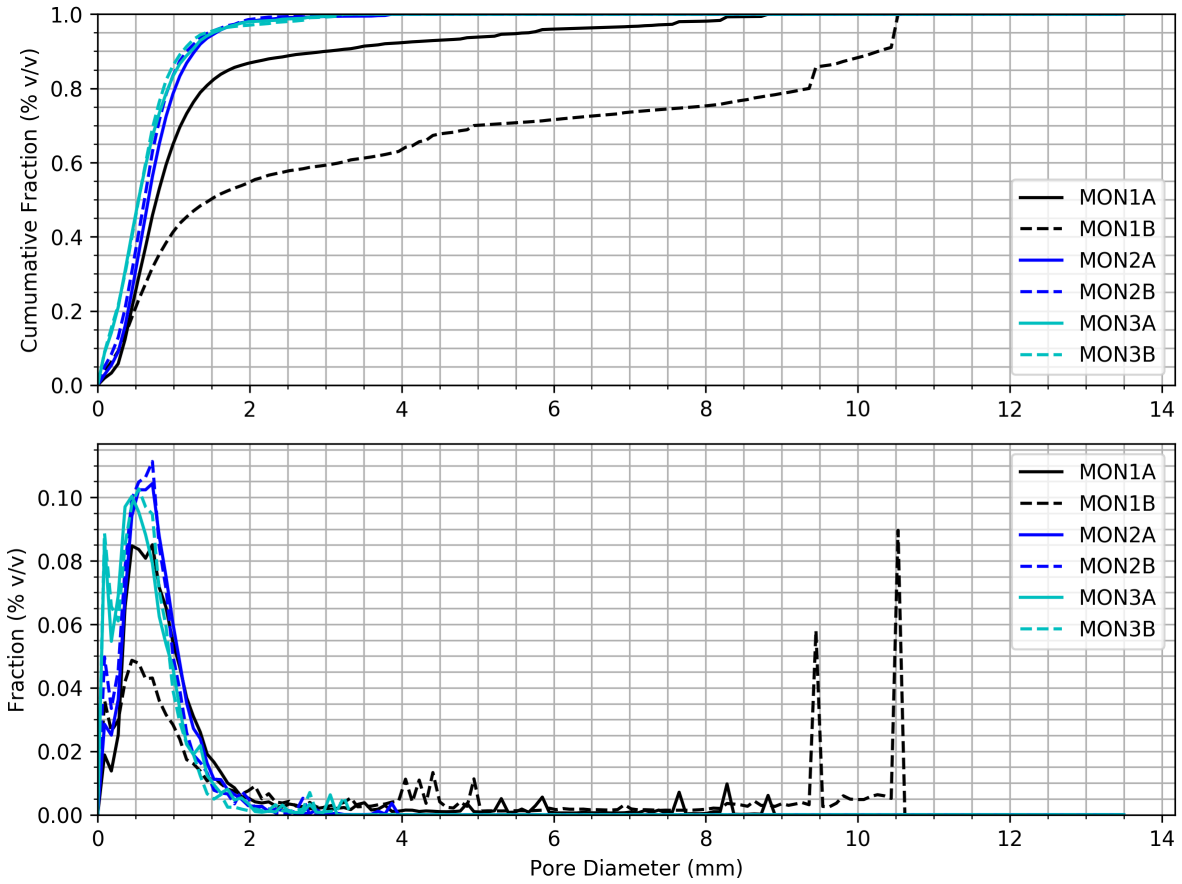

(b) Gravel layer

Figure 4: Cumulative (at the top) and frequency (at the bottom) PSD for the deposit layer and the gravel layer 


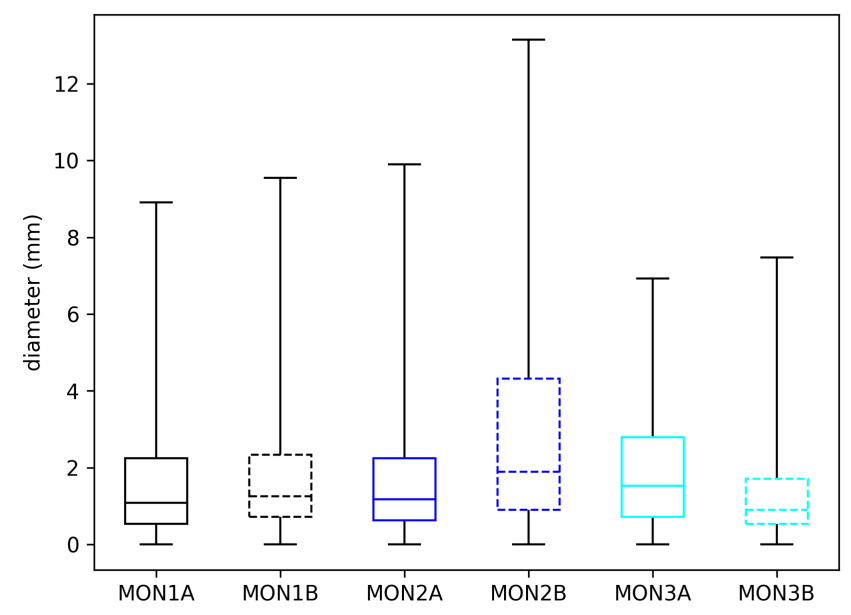

(a) Deposit layer

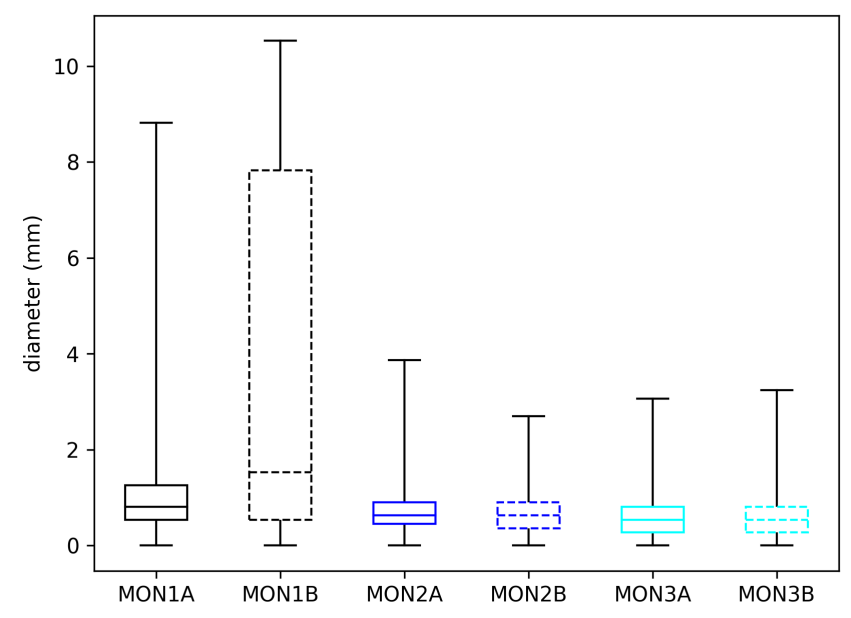

(b) Gravel layer

Figure 5: Pore Size Distribution (PSD) boxplots for the deposit layer and the gravel layer. Dash line indicates the presence of Phragmites. 


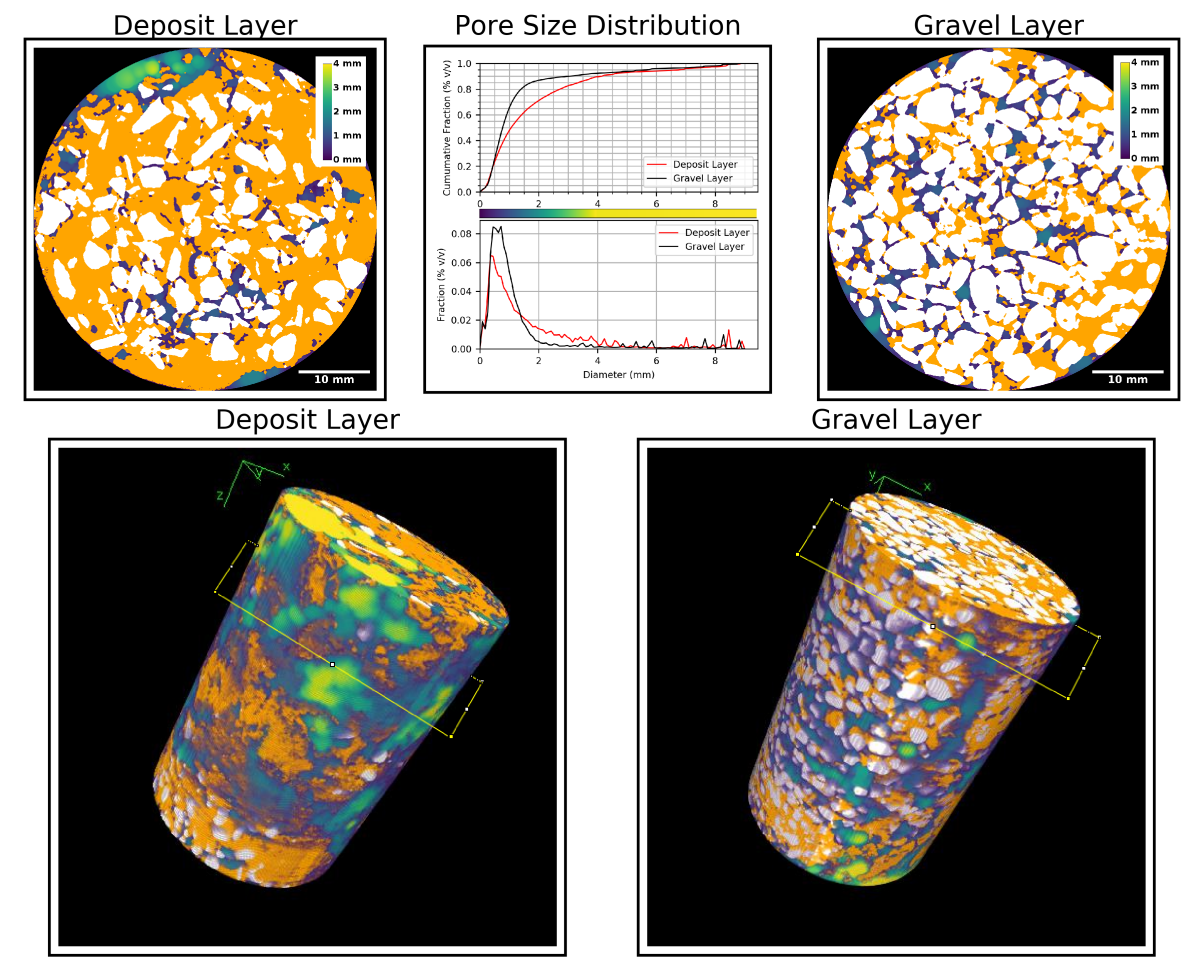

Figure 6: 3D rendering of pore local thickness map in the deposit layer and the gravel layer. 
diameter of the largest pores, which correspond to Phragmites (Figure $\sqrt{5}$.

Kim and Forquet (2016) describe a bi-modal distribution of pore size. The mode of larger pores they observed matches the one obtained in this study ( 0.5 $\mathrm{mm}$ ). The mode of the smaller pores in their work (near $50 \mu \mathrm{m}$ ) is almost at the same order of magnitude than the resolution of the scans in this study, explaining why those pores cannot be observed. This comparison must be interpreted very carefully as (i) the method used in Kim and Forquet (2016) to compute the PSD relies on a different algorithm (Dougherty et al., 2017), (ii) the pore-size distribution was calculated on 2D thin section images and (iii) the procedure to produce the thin sections may affect pore shape.

Compared to the thin section method, X-ray tomography provides three main advantages: (i) it provides 3D informations with an acceptable resolution for larger volumes, (four times the thickness of samples used for thin sections), (ii) 3D tortuosity and 3D pore connectivity can be studied (Rezanezhad et al. 2009), which gives a better description of the sample's morphology, and (iii) no sample pretreatment is needed.

The representativity of tomography has been discussed by comparing pore properties of different samples extracted at different locations in the filter. The heterogeneity within the sample and the smallest representative sample's diameter are discussed in the next section.

\subsection{Representative Elementary Volume (REV)}

The void-REV, biosolid-REV and gravel-REV are deduced by analyzing the convergence of the volume fractions to a constant value in Figure 7 . When convergence is reached, at a certain diameter of circular window, the volume fractions reach a plateau (i.e. plateau of region II in the work of CostanzaRobinson et al. (2011)) with a value close to the global volume fraction of the slice. This implies that the sample diameter is large enough to be spatially representative of the heterogeneities of phases distribution that can be observed at the pore scale. Results of this study indicate that a 2D-REV is reached in the deposit and gravel layers, as long as no reed is present in the 2D-slice and 


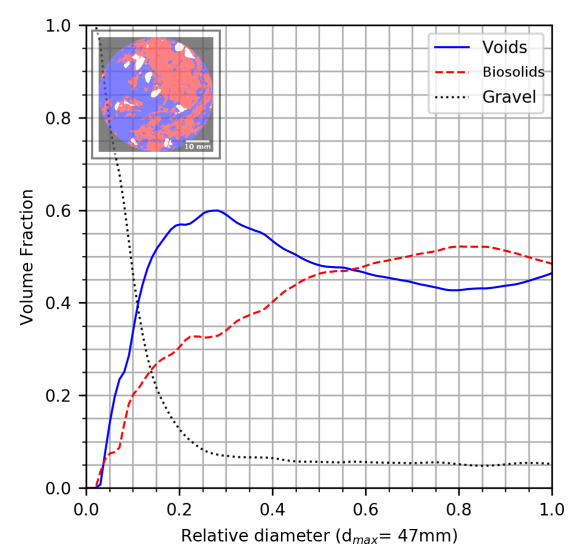

(a) Depth $=0 \mathrm{~mm}$

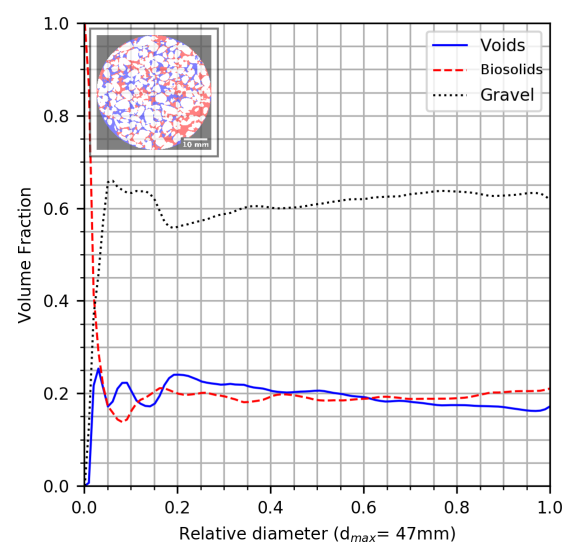

(c) Depth $=-85 \mathrm{~mm}$

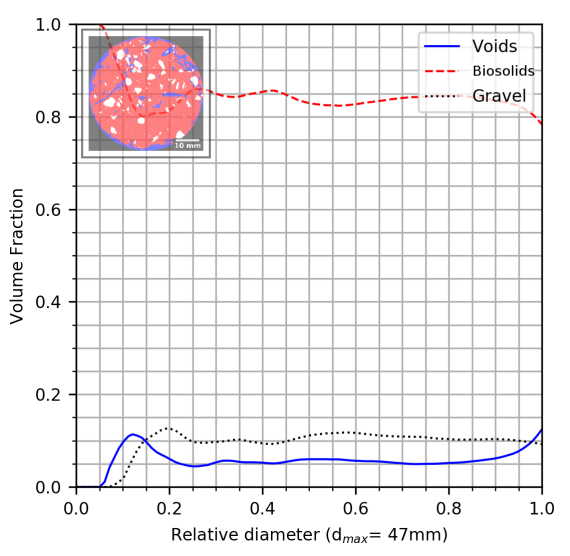

(b) Depth $=-45 \mathrm{~mm}$

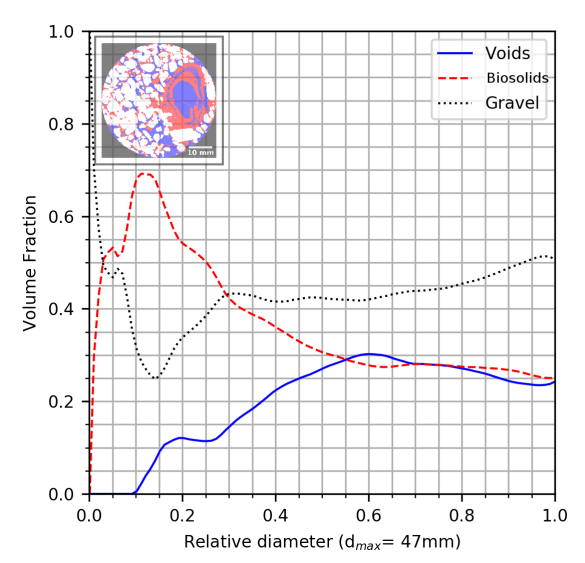

(d) Depth $=-124 \mathrm{~mm}$

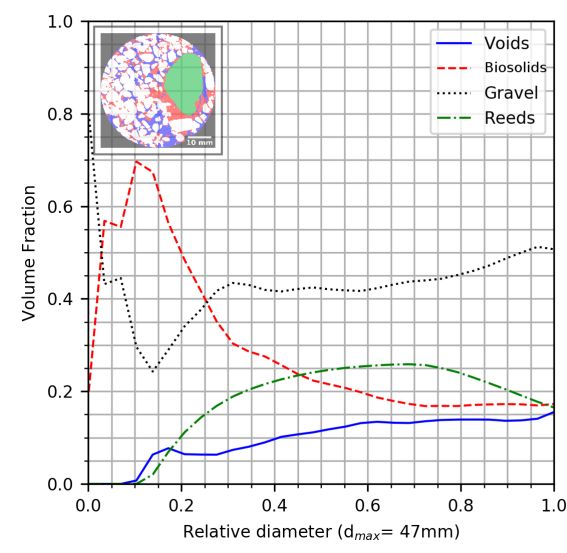

(e) Depth $=-124 \mathrm{~mm}$, four phase segmentation 27

Figure 7: Phase volume fraction versus relative diameter at four different depths 
the slice is not located near the surface. It seems that for phases with more than of volume fraction, $\mathrm{REV}$ is reached when variations are less than $\pm 5 \%$. For phases with less than $50 \%$ of volume fraction, REV is reached when variations are less $\pm 2.5 \%$. To our knowledge, this is the first time an analysis of the REV in Xray-CT on first-stage French VF wetlands has been conducteed. These results could be complemented by the analysis of the REV for other pore scale properties different than phase volume fraction (Al-Raoush and Papadopoulos, 2010).

Usually, REV assessments in pore scale studies focus on the porosity-REV (i.e. voids-REV). In this study, a particular attention is given to biosolids because most of the microbial activity and the treatment of water-soluble pollutants takes place in this phase (Molle, 2014). The gravel phase is studied as well as it has been observed that the compaction of the gravel layer decreases as biosolids are retained within the filter.

Figures 7a to $7 \mathrm{e}$ correspond to four different horizontal (perpendicular to the main water flow direction) 2D-slices taken in sample MON1A: two slices from the deposit layer (one at the top of the deposit and other at a location of maximal biosolid accumulation) and two slices from the gravel layer (with and without Phragmites identified inside the slice).

In Figures $7 \mathrm{~b}$ and $7 \mathrm{c}$, no Phragmites is present. The volume fractions for all the phases converge to a global value when the sub-sampling diameter reaches $57530 \%$ of the total diameter of the sample $(1.5 \mathrm{~cm})$. There are no large oscillations of the volume fractions beyond this point. The reader must be aware that this assessment remains mainly qualitative.

At the top of the deposit layer, the void and biosolid distributions are very heterogeneous. This reflects the fact that the surface of the deposit layer is naturally very irregular. As a consequence the curves for biosolid and void phases in Figure 7 a show no satisfactory convergence.

When a Phragmites is present, the biosolid and void distributions exhibit a high degree of heterogeneity, and thus no convergence is reached (figure 7e. For this slice, a manual segmentation of the reed was performed and is shown in 
green. Then the REV is deduced for the volume fraction of four phases (void, biosolid, gravel and Phragmites) in Figure $7 \mathrm{e}$. The convergence of the void and biosolid volume fractions occurs for smaller radius and a representative volume is reached at $70 \%$ of the total diameter of the sample. This does not affect the convergence for the gravel phase. This figure shows that Phragmites have an effect on the distribution of biosolids and gravels in its surroundings. It is then relevant to optimize the methodology presented here to obtain four phase segmentations of the samples in order to describe better the morphology of the samples.

For the study of pore scale phenomena using Xray-CT, results demonstrate that the representativity of the sample regarding phase volume fractions is achieved at sample diameters larger than $1.5 \mathrm{~cm}$ ( 7.5 times the size of $d_{10}$ of the gravels in this study). However, considering the sensibility of the samples to mechanical deformations during sampling, it is still recommended to extract samples of minimum $5 \mathrm{~cm}$ in diameter, which will give a security factor of more than three times the REV size observed in this study.

\section{Conclusion}

This study assesses the spatial representativity of pore-scale measurements obtained by Xray-CT of the filtering media in first-stage French VF treatment wetlands. Both the heterogeneity of phase distribution inside a single sample and the differences of pore scale properties between several samples of a treatment wetland have been considered. The results suggest that a sample diameter of $5 \mathrm{~cm}$ is large enough to (i) be representative of the heterogeneous phase distribution (voids, fouling material and gravel) at the pore scale, independently of the location of the sample and (ii) preserve the structure of the sample during the sampling by limiting shear stress impact at the core of the sample.

Prior to Xray-CT, the distribution of biosolids in a mature French VF treatment wetland was assessed based on electromagnetic measurements to select sampling points representative of its heterogeneity. FDEM allows a 2D- 
estimation of the biosolid distribution as electrical conductivity is highly correlated to the thickness of the deposit layer due to its high organic matter and water contents. The electrical conductivity measurements were found to be homogeneous over nearly $95 \%$ of the treatment wetland surface. This is explained probably by the age of the wetland and its good maintenance. The remaining 5 $\%$ of the surface showed high values of electrical conductivity in regions of $1 \mathrm{~m}$ in diameter around the feeding points which are explained by preferential water retention and biosolid accumulation at those locations. This information leads to the conclusion that large scale heterogeneities in biosolid distribution cannot be considered as a cause of non-representative Xray-CT for the treatment wetland in this study.

625 After scanning and segmenting the tomographies, the volume fraction and specific surface area vertical profiles are computed for all the samples. They show several similarities independently of the sampling point. All samples show a vertical stratification of these properties which results from the vertical filtration of wastewater in the treatment wetland. A special focus is put on the transition from the deposit layer to the gravel layer. In order to make better comparisons of pore scale properties, a criterion to delimit the deposit layer is introduced. The upper and lower limits of the deposit layer are located at the intersection of the of the void and biosolid volume fraction profiles and at the intersection of the biosolid and gravel volume fraction profiles, respectively.

${ }_{635}$ Though Xray-CT capture very well variation of these properties, samples are not found to be significantly different from each other in the context of first stage French VF treatment wetlands.

The global biosolid volume fraction for the deposit layer and the gravel layer, and the thickness of the deposit layer measured by Xray-CT show an ${ }_{640}$ interesting correlation with small variations of $\mathrm{EC}\left(>1 \mu S \cdot m^{-1}\right)$ measured by FDEM. This could be further exploited to characterize biosolid distribution in French VF treatment wetland being aware that the contributions to the EC measurement of organic matter, moisture, biosolid and gravel volume fractions and the thickness of the deposit layer cannot be distinguished solely by FDEM. 
Pore size distributions are similar for all samples; the mode and the range of pores size distribution depend only on the vertical location in the sample (deposit layer or gravel layer). The presence of Phragmites is the main cause of non-systematic differences between pore-scale properties of the samples.

A study of the 2D-REV at several depths was conducted for one of the samples. It consists in the analysis of the dependency of the average value of phase volume fractions (voids, biosolids and gravels) on the size of a sub-sampling circular window. Based on a qualitative assessment of this relationship, REV is estimated to be achieved at one third of the sample diameter $(1.6 \mathrm{~cm})$ when the analyzed depth does not include Phragmites or strongly heterogeneous features as observed near the top of the sample.

This study sets a solid base for the spatial representativity of further investigations on mechanisms that govern pore-scale filtration and biological treatment in French VF treatment wetlands, including water flow, as well as transport of particulate matter and dissolved oxygen. This is valid for mechanisms depending 660 predominantly on macropore structure, such as gravity driven flow, and advective/diffusive oxygen transport from the atmosphere to the biosolids during the feeding and rest period of the first-stage filters. 
Table 3: Comparison of different studies on treatment wetland Specific Surface Areas (SSA)

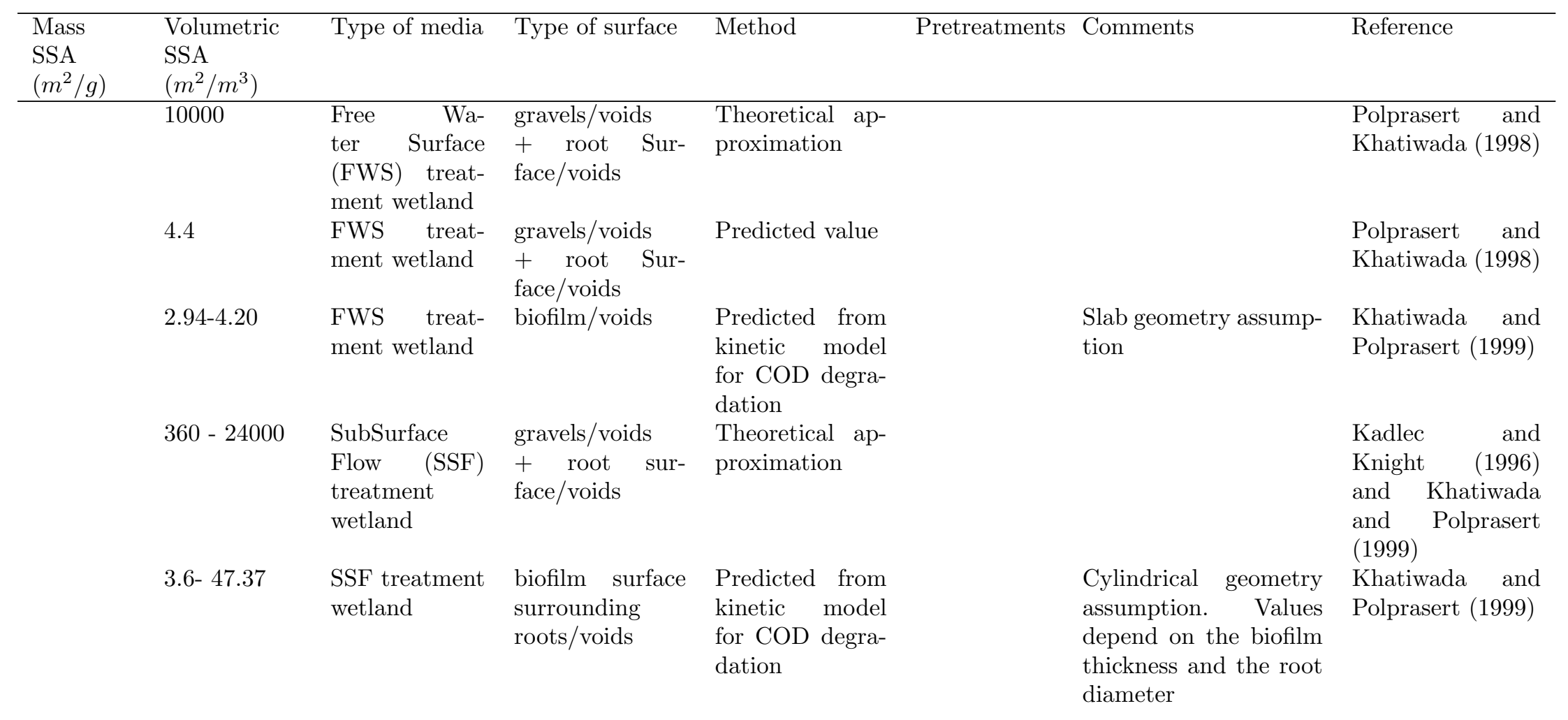




\begin{tabular}{|c|c|c|c|c|c|c|c|}
\hline $8.9 \times 10^{-4}$ & 810 & $\begin{array}{l}\text { SSF treatment } \\
\text { wetland }\end{array}$ & granules/voids & $\begin{array}{l}\text { water gravimet- } \\
\text { rical }\end{array}$ & None & $\begin{array}{l}\text { surface estimated from } \\
\text { water film thickness } \\
(10 \mu m-60 \mu m), \text { spher- } \\
\text { ical granules }\end{array}$ & $\begin{array}{lll}\text { Austin } & \text { et al. } \\
(2007) & & \end{array}$ \\
\hline \multirow[t]{2}{*}{$13.5-218$} & $\begin{array}{l}1.35 \times 10^{7}- \\
21.8 \times 10^{7}-6\end{array}$ & $\begin{array}{l}\text { Deposit of } \\
\text { French VF } \\
\text { treatment } \\
\text { wetlands }\end{array}$ & deposit/voids & $\begin{array}{l}\text { Dynamic vapor } \\
\text { sorption }\end{array}$ & $\begin{array}{l}\text { Drying } \quad(1 \\
\left.\text { day, } 35 \quad{ }^{\circ} \mathrm{C}\right) \\
+ \text { sieving }(1 \\
\text { mm })\end{array}$ & Mixing samples & $\begin{array}{lll}\text { Kania } & \text { et } & \text { al. } \\
2018 & & \end{array}$ \\
\hline & $100-1000$ & $\begin{array}{l}\text { deposit } \quad+ \\
\text { gravel French } \\
\text { VF Treatment } \\
\text { Wetland }\end{array}$ & Biosolids/voids & Tomography & None & $\begin{array}{l}\text { Depending on the } \\
\text { depth of the sample }\end{array}$ & This study \\
\hline
\end{tabular}




\section{References}

Al-Raoush, R., Papadopoulos, A., 2010. Representative elementary volume analysis of porous media using X-ray computed tomography. Powder Technology 200, 69-77. URL: http://www.sciencedirect.com/science/article/ pii/S0032591010000859, doi 10.1016/j.powtec.2010.02.011.

Austin, D., Maciolek, D., Davis, B., Wallace, S., 2007. Damköhler number design method to avoid clogging of subsurface flow constructed wetlands by

670 heterotrophic biofilms. Water Science and Technology 56, 7-14. doi 10.2166/ wst.2007.493.

Bhattad, P., Willson, C.S., Thompson, K.E., 2013. Segmentation of Lowcontrast Three-phase X-ray Computed Tomography Images of Porous Media, in: Advances in Computed Tomography for Geomaterials. John Wiley \& Sons,

675 Inc., pp. 254-261. URL: http://dx.doi.org/10.1002/9781118557723. ch30, doi $10.1002 / 9781118557723 . \operatorname{ch} 30$.

Calamita, G., Perrone, A., Brocca, L., Onorati, B., Manfreda, S., 2015. Field test of a multi-frequency electromagnetic induction sensor for soil moisture monitoring in southern Italy test sites. Journal of Hydrology 529,

680 \316-329. URL: http://www.sciencedirect.com/science/article/pii/ S002216941500520X doi 10.1016/j.jhydrol.2015.07.023.

Callegary, J.B., Leenhouts, J.M., Paretti, N.V., Jones, C.A., 2007. Rapid estimation of recharge potential in ephemeral-stream channels using electromagnetic methods, and measurements of channel and vegetation characteristics. Journal of Hydrology 344, 17-31. URL: http://www.sciencedirect. a com/science/article/pii/S0022169407003502, doi:10.1016/j.jhydrol. 2007.06 .028

Chang, C., Zhou, Q., Kneafsey, T.J., Oostrom, M., Wietsma, T.W., $\mathrm{Yu}, \mathrm{Q}$, 2016. Pore-scale supercritical CO2 dissolution and mass trans${ }_{690}$ fer under imbibition conditions. Advances in Water Resources 92, 

S0309170816300811, doi $10.1016 / \mathrm{j}$.advwatres.2016.03.015.

Chazarenc, F., Gagnon, V., Comeau, Y., Brisson, J., 2009. Effect of plant and artificial aeration on solids accumulation and biological activities in constructed wetlands. Ecological Engineering 35, 1005-1010. URL: http://www.sciencedirect.com/science/article/pii/ S0925857408001468, doi $10.1016 / \mathrm{j}$. ecoleng.2008.07.008

Clement, R., Audebert, M., Loisel, S., Moreau, S., 2018. Straightforward assessment of horizontal leachate injection system using frequency domain electromagnetic induction method. Environmental Research and Technology 1, 13-17. URL: https://dergipark.org.tr/tr/pub/ert/390036.

Costanza-Robinson, M.S., Estabrook, B.D., Fouhey, D.F., 2011. Representative elementary volume estimation for porosity, moisture saturation, and air-water interfacial areas in unsaturated porous media : Data quality implications 47, 1-12. doi:10.1029/2010WR009655.

Doolittle, J.A., Brevik, E.C., 2014. The use of electromagnetic induction 口)

sciencedirect.com/science/article/pii/S0016706114000548, doi:10. $1016 / j \cdot g e o d e r m a .2014 .01 .027$

Dotro, G., Langergraber, G., Molle, P., Nivala, J., Puigagut, J., Stein, O., Sperling, M.v., 2017. Treatment wetlands. Number Volume 7 in Biological wastewater treatment series, IWA Publishing, London. OCLC: ocn984563578.

Dougherty, B., Schindelin, J., Doube, M., Domander, R., Hiner, M., Rueden, 口 C., Coeurjolly, D., Kunzelmann, K.H., 2017. Local Thickness. URL: http: 715 //imagej.net/Local_Thickness.

Forquet, N., Morvannou, A., Molle, P., Vanclooster, M., 2011. Imaging of vertical flow constructed wetland using electrical resistivity tomography and 
time domain reflectometry, Joint meeting of Society of Wetland Scientists, WETPOL and Wetland Biochemistry Symposium, Prague, Czech Republic.

Hashemi, M.A., Khaddour, G., François, B., Massart, T.J., Salager, S., 2014. A tomographic imagery segmentation methodology for three-phase geomaterials based on simultaneous region growing. Acta Geotech. 9, 831-846.

URL: http://link.springer.com/10.1007/s11440-013-0289-5, doi 10 . 1007/s11440-013-0289-5.

Hildebrand, T., Rüegsegger, P., 1997. A new method for the model-independent assessment of thickness in three-dimensional images. Journal of Microscopy a 185, 67-75. URL: https://onlinelibrary.wiley.com/doi/abs/10.1046/

a j.1365-2818.1997.1340694.x doi 10.1046/j.1365-2818.1997.1340694. $\mathrm{x}$.

${ }_{730}$ Kadlec, R., Knight, R., 1996. Treatment Wetlands. Boca Raton, Florida.

Kania, M., Gautier, M., Michel, P., Gourdon, R., 2018. Study of aggregation in surface sludge deposits from 14 full-scale French constructed wetlands using particle size distribution and dynamic vapor sorption analyses. Water Science and Technology 77, 79-90. doi:10.2166/wst.2017.523.

Khatiwada, N.R., Polprasert, C., 1999. Assessment of effective specific surface area for free water surface constructed wetlands. Water Science and

n Technology 40, 83-89. URL: http://dx.doi.org/10.1016/S0273-1223(99) 00443-6, doi:10.1016/S0273-1223(99)00443-6.

Kim, B., Forquet, N., 2016. Pore-scale observation of deposit within the gravel matrix of a vertical flow constructed wetland. Environmental Technology 37, 3146-3150. URL: https://doi.org/10.1080/09593330.2016.1178334, doi: $10.1080 / 09593330.2016 .1178334$

Knowles, P., Dotro, G., Nivala, J., García, J., 2011. Clogging in subsurfaceflow treatment wetlands: Occurrence and contributing factors. Ecological 
Engineering 37, 99-112. URL: http://www.sciencedirect.com/science/ article/pii/S0925857410002600, doi 10.1016/j.ecoleng.2010.08.005.

Lardo, E., Arous, A., Palese, A.M., Nuzzo, V., Celano, G., 2016. Electromagnetic induction: A support tool for the evaluation of soil CO2 emissions and soil organic carbon content in olive orchards under semi-arid conditions.

Geoderma 264, 188-194. URL: http://www.sciencedirect.com/science/ article/pii/S0016706115301087, doi 10.1016/j.geoderma.2015.10.014

Legland, D., Kiêu, K., Devaux, M.F., 2011. Computation of Minkowski Measures on 2d and 3d Binary Images. Image Analysis \& Stereology 26, 83. URL: https://www.ias-iss.org/ojs/IAS/article/view/811, doi:10. 5566/ias.v26.p83-92

Lehmann, G., Legland, D., 2012. Efficient N-Dimensional surface estimation using Crofton formula and run-length encoding. The Insight Journal , 852URL: http://hdl.handle.net/10380/3342, revision: 2 .

Li, J.H., Zhang, L.M., Wang, Y., Fredlund, D.G., 2009. Permeability tensor and representative elementary volume of saturated cracked soil. Can. Geotech.

¿ J. 46, 928-942. URL: https://www.nrcresearchpress.com/doi/10.1139/ T09-037, doi:10.1139/T09-037.

Lombard-Latune, R., Pelus, L., Fina, N., L'Etang, F., Le Guennec, B., Molle, P., 2018. Resilience and reliability of compact vertical-flow treatment wetlands designed for tropical climates. Science of The Total Environment 642,

(208-215. URL: http://www.sciencedirect.com/science/article/pii/ S0048969718320989, doi $10.1016 /$ j.scitotenv.2018.06.036.

Martinez-Carvajal, G.D., Oxarango, L., Adrien, J., Molle, P., Forquet, N., 2019. Assessment of X-ray Computed Tomography to characterize filtering media from Vertical Flow Treatment Wetlands at the pore scale. Science of the Total

1) Environment 658, 178-188. URL: https://doi.org/10.1016/j.scitotenv. 2018.12.119, doi:10.1016/j.scitotenv.2018.12.119. 
de Matos, M.P., von Sperling, M., de Matos, A.T., 2018. Clogging in horizontal subsurface flow constructed wetlands: influencing factors, research

$$
\text { s11157-018-9458-1. }
$$

McNeill, D., 1980. Electromagnetic terrain conductivity measurements at low induction numbers. Technical Report Technical Note TN-6. GEONICS. URL: http://geonics.com/pdfs/technicalnotes/tn6.pdf

Molle, P., 2014. French vertical flow constructed wetlands: a need of a better understanding of the role of the deposit layer. Water Sci Tech-

घ nol 69, 106-112. URL: https://iwaponline.com/wst/article/69/ 1/106/18153/French-vertical-flow-constructed-wetlands-a-need, doi:10.2166/wst.2013.561.

Molle, P., Liénard, A., Boutin, C., Merlin, G., Iwema, A., 2005. How to treat raw sewage with constructed wetlands: An overview of the French systems. Water Science and Technology 51, 11-21.

Morvannou, A., 2011. Dynamic modelling of nitrification in vertical flow constructed wetlands. PhD Thesis. Universit Catholique de Louvain.

Morvannou, A., Forquet, N., Michel, S., Troesch, S., Molle, P., 2015. Treatment performances of French constructed wetlands: results from a database collected over the last 30 years. Water Sci Technol 71,

n 1333-1339. URL: https://iwaponline.com/wst/article/71/9/1333/ 795 a 18617/Treatment-performances-of-French-constructed doi 10.2166/ wst.2015.089.

Nivala, J., Knowles, P., Dotro, G., García, J., Wallace, S., 2012. Clogging in subsurface-flow treatment wetlands: Measurement, modeling and management. Water Research 46, 1625-1640. doi:10.1016/j.watres.2011.12.051 
Pilny, V., Janacek, J., 2006. Anisotropic Diffusion 2D. URL: https://imagej . nih.gov/ij/plugins/anisotropic-diffusion-2d.html.

Polprasert, C., Khatiwada, N.R., 1998. An integrated kinetic model for water hyacinth ponds used for wastewater treatment. Water Research 32, 179-185. doi $10.1016 /$ S0043-1354(97)00191-7.

Poots, V.J.P., McKay, G., 1979. The specific surfaces of peat and wood.

1 Journal of Applied Polymer Science 23, 1117-1129. URL: https: //onlinelibrary.wiley.com/doi/abs/10.1002/app.1979.070230416, doi:10.1002/app.1979.070230416.

Ramírez, M.P.O., Oxarango, L., Strozzi, A.G., 2019. Effect of X-ray CT resolution on the quality of permeability computation for granular soils: definition of a criterion based on morphological properties. Soil Res. 57, 589-600. URL: https://www.publish.csiro.au/sr/SR18189, doi:10.1071/SR18189

Rezanezhad, F., Quinton, W.L., Price, J.S., Elrick, D., Elliot, T.R., Heck, R.J., 2009. Examining the effect of pore size distribution and shape on flow through unsaturated peat using 3-D computed tomography. Hydrology and Earth System Sciences Discussions 6, 3835-3862. doi 10.5194/hessd-6-3835-2009.

Rosato, A., Strandburg, K.J., Prinz, F., Swendsen, R.H., 1987. Why the Brazil nuts are on top: Size segregation of particulate matter by shaking.

a Phys. Rev. Lett. 58, 1038-1040. URL: https://link.aps.org/doi/10. 1103/PhysRevLett.58.1038, doi:10.1103/PhysRevLett.58.1038.

Saito, T., Toriwaki, J.I., 1994. New algorithms for euclidean distance transformation of an n-dimensional digitized picture with

1 applications. Pattern Recognition 27, 1551-1565. URL: http: //www.sciencedirect.com/science/article/pii/0031320394901333, doi:10.1016/0031-3203(94)90133-3.

Santaló, L.A., 2004. Integral Geometry and Geometric Probability. 2 ed., ₫ Cambridge University Press, Cambridge. URL: https://www.cambridge. 
Schindelin, J., Arganda-Carreras, I., Frise, E., Kaynig, V., Longair, M., Pietzsch, T., Preibisch, S., Rueden, C., Saalfeld, S., Schmid, B., Tinevez, J.Y., White, D.J., Hartenstein, V., Eliceiri, K., Tomancak, P., Cardona, A., 2012. Fiji: an open-source platform for biological-image analysis. Nat Methods 9, 676-682. URL: https://www.nature.com/articles/nmeth.2019, doi:10.1038/nmeth. 2019 .

Sundaravadivel, M., Vigneswaran, S., 2001. Constructed Wetlands for Wastewater Treatment. Critical Reviews in Environmental Science and Technology 31, 351-409. URL: https://doi.org/10.1080/20016491089253, doi:10.1080/20016491089253.

840 Szafranek-Nakonieczna, A., Bennicelli, R.P., 2010. Ability of peat soil to oxidize methane and affect temperature and layer deposition. Polish Journal of Environmental Studies 19, 805-810.

Tschumperl, D., Deriche, R., 2003. Vector-valued Image Regularization with PDE's: A Common Framework for Different Applications, in: Proceedings of the 2003 IEEE Computer Society Conference on Computer Vision and Pattern Recognition, IEEE Computer Society, Washington, DC, USA. pp. 651-656. Event-place: Madison, Wisconsin.

Van Rossum, G., Drake Jr, F.L., 1995. Python tutorial. Centrum voor Wiskunde en Informatica Amsterdam, The Netherlands.

Zhang, D., Zhang, R., Chen, S., Soll, W.E., 2000. Pore scale study of flow in porous media: Scale dependency, REV, and statistical REV. Geophysical

₫ Research Letters 27, 1195-1198. URL: https://agupubs.onlinelibrary. wiley.com/doi/abs/10.1029/1999GL011101, doi:10.1029/1999GL011101. 


\section{Acknowledgements}

855 The authors would like to thanks Jérémie Aubert et Clément Crétollier for their technical assistance and Jaime Nivala for editing the manuscript into proper scientific English. 